\title{
Rheological Analysis of the Phenolic and Furfuryl Resins Used in
}

\section{the Carbon Materials Processing}

\author{
Edson Cocchieri Botelho $^{a_{*},}$, Natália Scherbakoff ${ }^{b}$, \\ Mirabel Cerqueira Rezende ${ }^{\mathrm{c}}$ \\ ${ }^{\mathrm{a}}$ Centro Técnico Aeroespacial/Instituto Tecnológico de Aeronáutica, \\ Departamento de Física, 12.228-901 São José dos Campos - SP, Brasil \\ ${ }^{\mathrm{b}}$ Rhodia Poliamidas América do Sul, 09842-080 São Bernardo do Campo - SP, Brasil \\ ${ }^{\mathrm{c}}$ Centro Técnico Aeroespacial/Instituto de Aeronáutica e Espaço \\ Divisão de Materiais, 12.228-904 São José dos Campos - SP, Brasil
}

Received: May 25, 1999 Revised: January 11, 2000

\begin{abstract}
Carbon materials processing is an advanced technology due to its aerospace and medical applications. In the aerospace area one can mention the carbon/carbon composites used in rockets and aeronautical brakes; in the medical area one can mention the intrabody implant tools such as heart and hydrocephalic valves and pacemaker electrode tips. The highly sophisticated purpose of its application requires a very tight processing control, which defines the microstructure the mechanical, thermal and electrical characteristics of the final material. The objective of this study is to correlate rheological, chromatographic and thermal analysis of phenolic and furfuryl resins, aiming their use as raw materials in carbon/carbon composite and glassy carbon processing. The obtained results are correlated and used directly in the establishment of the adequate parameters for carbon reinforcement impregnation and to prepare glassy carbon samples with controlled porosity.
\end{abstract} carbon

Keywords: rheological analysis, thermosets, carbon/carbon composites and glassy

\section{Introduction}

Carbon Materials (CM) are constituted essentially by carbon atoms, which can be combined indefinitely in order to originate different structures; these structures can be changed by processing conditions and by using different organic raw materials. The possibility of obtaining desired properties for each application by choosing raw materials or optimizing process conditions imparts to $\mathrm{CM}$ a promising future among the new materials ${ }^{1-3}$.

The physical-mechanical properties (such as density, mechanical resistance, electrical conductivity, thermal resistance, etc.) of the advanced carbon materials have allowed application to the aerospace, nuclear, sports and medical industries such as low density mirrors, rocket nozzle throats, aircraft brakes, external and internal implants, sports articles, electronics, chemical and siderurgical products ${ }^{3}$. Among $\mathrm{CM}$ for strategic uses are the Carbon Fiber Reinforced Carbon composites (carbon/carbon composites or CFRC) and the glassy carbon ${ }^{4}$.

ae-mail: edsonbotelho@yahoo.com

be-mail: nataliascherbakoff@fw.rationale.com.br

e-mail: mirabelrezende@hotmail.com
Carbon/carbon composites are constituted of a carbon matrix reinforced with carbon fibers ${ }^{3-5}$. One of the steps of processing carbon/carbon composites is the liquid impregnation of the reinforcement with thermoset resins rich in carbon residue $(\sim 50 \% \mathrm{w} / \mathrm{w})$ and pitches ${ }^{3,6}$. The most used thermosets are phenolic and furfuryl resins ${ }^{2}$.

Although named glassy carbon, this material can not be considered a glass from a crystallographic point of view, due to the biorientation arrangements of its carbon atoms. The glassy denomination comes from the glassy appearance of the material after polishing and also due to the brittle fracture similar to the glass (conchoidal type). This CM class is characterized by closed porosity obtained during the processing, which determines the fracture behavior of the glassy carbon ${ }^{3,7}$.

The knowledge of certain characteristics of the precursor polymer, such as molecular weight distribution, average molecular weight and rheological behavior, orientates the processing conditions in order to control the porous size and its quantity in the carbon matrix and, consequently, the final 
mechanical, electrical and thermal properties of the $\mathrm{CM}^{8-15}$. In this work, rheological characteristics of phenolic and furfuryl resins are determined and used to help the selection of the appropriate raw material and to establish the parameters for processing CRFC and glassy carbon.

\section{Materials and Methods}

Three Brazilian phenolic and one furfuryl resins were studied. The phenolic resins were two of the novolac type (codes $A$ and $B$ ) and one resol (code $C$ ). These resins presented a carbon yield after heat treatment at $1000{ }^{\circ} \mathrm{C}$ and $\mathrm{N}_{2}$ atmosphere (carbonization treatment) of $28.8 \%, 34.7 \%$ and $41.0 \%(\mathrm{w} / \mathrm{w})$, respectively ${ }^{11}$ and up to $3.0 \%$ of moisture. The moisture content was determined by the conventional Karl Fisher technique. The two novolac resins (each containing $9.5 \% \mathrm{wt}$ of hexamethylenetetramine) and the resol were cured at the temperature range of $60-180^{\circ} \mathrm{C}$.

The furfuryl resin (code $D$ ) used in this study presented a moisture content of $2.0 \%$ and carbon yield equal to $40 \%$ $(w / w)$. This resin was cured using $1.9 \%$ wt of p-toluenesulphonic acid solution $(60 \% \mathrm{w} / \mathrm{v})$, at three different temperatures 50, 60 and $70{ }^{\circ} \mathrm{C}$, during $15 \mathrm{~h}$. The polymerized furfuryl resin samples were characterized by optical microscopy assisted by image analyses.

Size exclusion chromatography (SEC) analyses were run in a HP equipment 1090 using THF as solvent, injection volume of $40 \mu \mathrm{L}$, continuous flow of $1.0 \mathrm{~mL} / \mathrm{min}$ and three columns (pores size distribution of $500 \AA, 100 \AA, 100 \AA$ ). The detector was an ultraviolet at $\lambda=254 \mathrm{~nm}$. As calibration was used polystyrene standard with molecular weight 28,$000 ; 12,500 ; 7,600 ; 3,770 ; 1,800 ; 1,050$, benzene and ethylbenzene.

Rheological measurements were performed on a controlled stress rheometer Rheometrics SR200, with $25 \mathrm{~mm}$ parallel plates and a $0.498 \mathrm{~mm}$ gap, frequency of $1 \mathrm{rad} / \mathrm{s}$ and stress equal to 5.0 Pa.s. The isothermal runs were obtained at $100{ }^{\circ} \mathrm{C}$ for the phenolic resins and at 50,60 and $70{ }^{\circ} \mathrm{C}$ for the furfuryl resin. These temperatures were chosen based on the initial temperature of resin polymerization using a Perkin Elmer Differential Scanning Calorimetry (DSC), series 7 , at a heating rate of $10^{\circ} \mathrm{C} / \mathrm{min}$ under nitrogen atmosphere.

\section{Results and Discussion}

The phenolic resin DSC results (Table 1) show that the initial temperature for the polymerization is located in the range of $106-110{ }^{\circ} \mathrm{C}$ and the final temperature is in the range of $172-176{ }^{\circ} \mathrm{C}$. These results fixed the rheological analysis for the phenolic resins at $100{ }^{\circ} \mathrm{C}$ and the final temperature of polymerization at $180^{\circ} \mathrm{C}$. The furfuryl resin showed a polymerization initial temperature at $44{ }^{\circ} \mathrm{C}$ and the final at $158{ }^{\circ} \mathrm{C}$ (Table 1). These results are due to the fact that the phenolic and the furfuryl resins present differ-
Table 1. DSC results for the phenolic and furfuryl resins.

\begin{tabular}{lccc}
\hline Resins & $\begin{array}{c}\text { Initial } \\
\text { temperature } \\
\left({ }^{\circ} \mathrm{C}\right)\end{array}$ & $\begin{array}{c}\text { Onset } \\
\text { temperature } \\
\left({ }^{\circ} \mathrm{C}\right)\end{array}$ & $\begin{array}{c}\text { Final } \\
\text { temperature } \\
\left({ }^{\circ} \mathrm{C}\right)\end{array}$ \\
\hline Phenolic A & 110 & 128 & 175 \\
Phenolic B & 106 & 131 & 172 \\
Phenolic C & 109 & 151 & 176 \\
Furfuryl D & 44 & 59 & 158 \\
\hline
\end{tabular}

ent polymerization reaction kinetics with reticulation temperature proper to each type of polymer. For the same reason, the onset temperatures (temperature of $50 \%$ of polymerization reaction conversion) of the phenolic resins $\left(128-151^{\circ} \mathrm{C}\right)$ were larger than the furfuryl resin $\left(59^{\circ} \mathrm{C}\right)$.

The rheological analysis were carried out aiming to know the gelification time (gel time) using the fact that at this gel time, the storage moduli $\left(G^{\prime}\right)$ is equal to loss moduli (G"). Figure 1 illustrates the rheological parameters, storage moduli, loss moduli and complex viscosity $\left(\eta^{*}\right)$ of the phenolic samples obtained at $100{ }^{\circ} \mathrm{C}$. Figure 2 shows the rheological parameters of the furfuryl resin obtained at 50 , 60 e $70^{\circ} \mathrm{C}$. Isothermal rheological curves were not obtained at $40{ }^{\circ} \mathrm{C}$, because previous experiments showed that this resin takes more than $15 \mathrm{~h}$ at this temperature to become solid. The behavior showed in Figs. 1 and 2 was expected because the samples were liquids of very low molecular weight as determined by chromatographic analysis (Table 2 ) and presented at the literature ${ }^{16-18}$. In this case, the transducer of the equipment did not have enough sensitivity to measure this low viscosity. This same explanation applies to the linear region and to the null values of the storage and loss modulus up to regions near the gel time. The increase after the gel time is due to the formation of crosslinked which lead to the solidification.

The isothermal rheograms and the gel time (or gel point) of the phenolic samples A, B and C are similar, being 7413, 7383 and $7333 \mathrm{~s}$, respectively. The rheological results show an increase of the complex viscosity after the range of 5000-6000 s due to the increase of the crosslink bonds density of the resin system.

The isothermal rheograms at 50,60 and $70{ }^{\circ} \mathrm{C}$ and the gel time of the furfuryl resin samples are different being 1200, 948 and 183 s, respectively (Fig. 2). Correlating the rheological analysis and DSC results obtained for the phenolic and furfuryl resins, it can be observed that the gel time of the phenolic resin was longer than the furfuryl. Also, the initial temperature of polymerization of the furfuryl resin is too low as compared with the phenolic resin. Considering that the CRFC processing involves several steps, such as reinforcement preparation, vacuum/pressure cycles, system heating, the resin choice must consider the initial 
temperature of polymerization and the gel time. This way the CRFC processing steps can be executed with safety and reliability.

Moreover, the $\overline{\mathrm{Mw}}$ results show that the furfuryl resin had longer values than the phenolic samples, consequently, its viscosity must be large. Obviously, this approach can make the carbon reinforcement impregnation more difficult. Then, from these data it is possible to choose the phenolic type as the most adequate sample to be used as impregnant in the CRFC processing. Among the three types of phenolic resins the sample $\mathrm{C}$ had the largest carbon yield $(41.0 \%)$ indicating that the CRFC process will be more efficient.
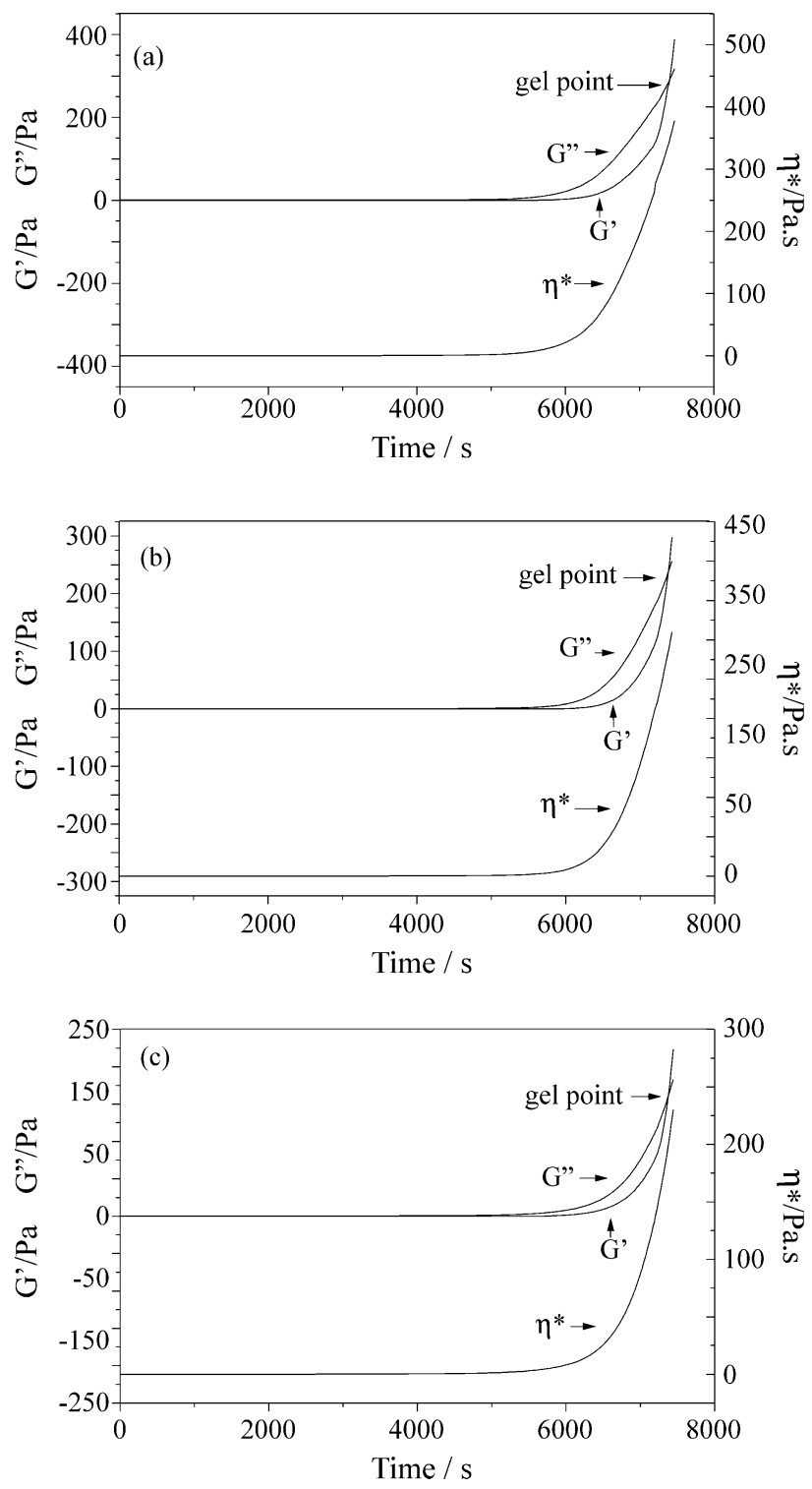

Figure 1. Isothermal rheograms at $100{ }^{\circ} \mathrm{C}$ : a) resol resin C; b) novolac resin A and c) novolac resin B.
The rheological analysis of the furfuryl resin show that this resin treated at $70{ }^{\circ} \mathrm{C}$ presented a faster polymerization reaction than the samples treated at 50 and $60^{\circ} \mathrm{C}$, increasing the crosslink bonds in a shorter time. Consequently, at 70 ${ }^{\circ} \mathrm{C}$ the porosity increases more due to the trapping of the larger quantity of volatile in the polymerized material (Fig. 3 ). This figure illustrates the differences in the macropore structure of the polymerized samples and the increasing amount of total fractional porosity determined by image analysis (Table 3). Porosity was characterized considering the opened macropores of circular cross section distributed on the glassy carbon surface. This analyse allowed to obtain the total porosity, as the fractional area occupied by pores,
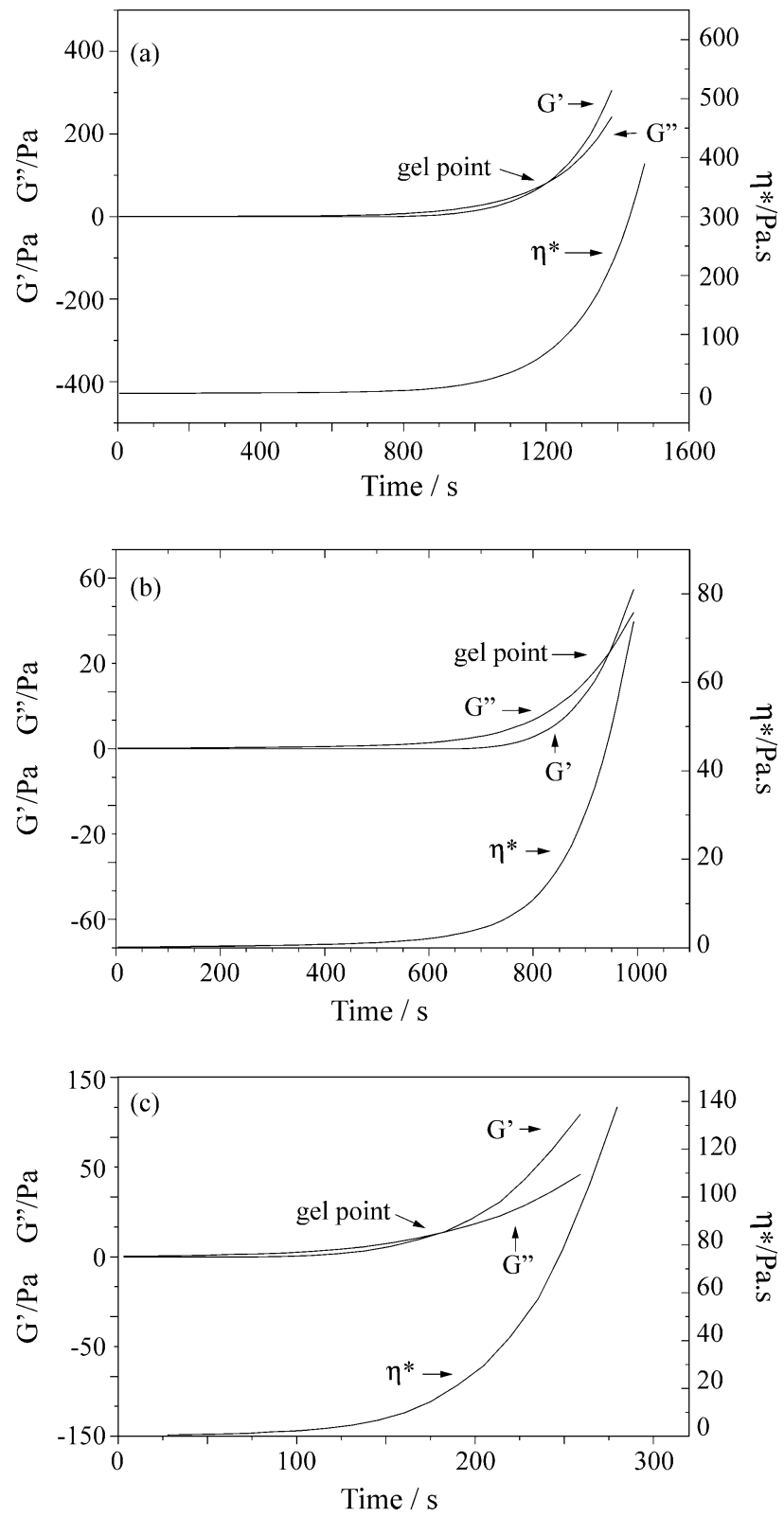

Figure 2. Isothermal rheograms: a) of the furfuryl resin at $50{ }^{\circ} \mathrm{C}$; b) at $60{ }^{\circ} \mathrm{C}$ and c) $70{ }^{\circ} \mathrm{C}$. 
Table 2. SEC results for the phenolic and furfuryl resins.

\begin{tabular}{lcc}
\hline Resins & $\overline{\mathrm{M}} \mathrm{w}(\mathrm{g} / \mathrm{mol})$ & $\overline{\mathrm{M}} \mathrm{w} / \overline{\mathrm{M}} \mathrm{n}$ \\
\hline Novolac A & 674 & 1.88 \\
Novolac B & 511 & 1.60 \\
Resol C & 686 & 1.83 \\
Furfuryl D & 5685 & 3.90 \\
\hline
\end{tabular}
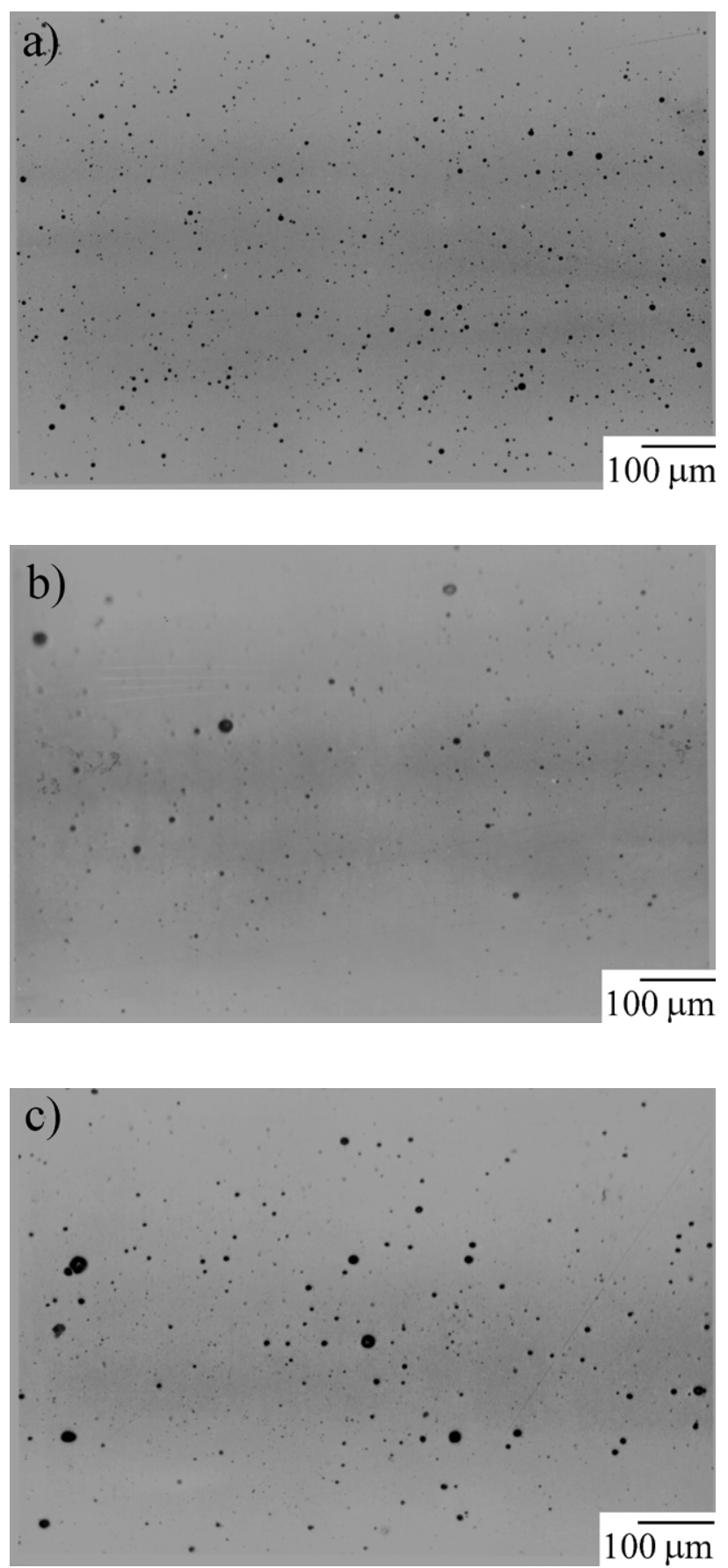

the pore area size distribution and the greater fractional porosity (more representative fraction of pores) (Table 3).

Photomicrography 3(a) is representative of the furfuryl samples treated at $50^{\circ} \mathrm{C}$. This figure shows a homogeneous distribution of isolated opened macropores. The image analysis (Fig. 3(a)) shows that the total porosity of the analysed surface is nearly $1.10 \%$ (Table 3 ). The pore size distribution is located in a range of $20-85 \mu \mathrm{m}^{2}$. However,
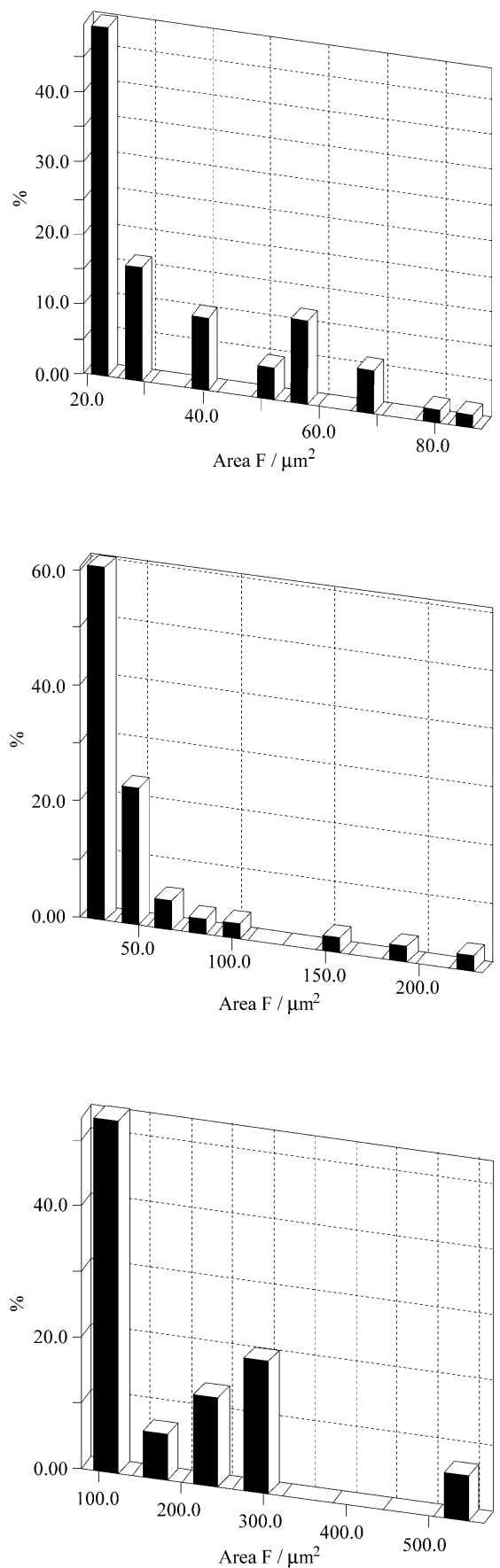

Figure 3. Optical microscopy analysis and pore size distribution histograms: a) the furfuryl resin at $50{ }^{\circ} \mathrm{C}$; b) $60^{\circ}$ and c) $70{ }^{\circ} \mathrm{C}$. 
the average pore size of $20 \mu \mathrm{m}^{2}$ represents the greater fractional porosity area $(50 \%)$ among the pores of the sample.

Figure $3 \mathrm{~b}$ shows the photomicrography and the histogram of the sample treated at $60{ }^{\circ} \mathrm{C}$. Unlike what was expected, this sample presents a total porosity of approximately $1.01 \%$. But the pore size is distributed in the range of $60-220 \mu \mathrm{m}^{2}$. The average pore size of $40 \mu \mathrm{m}^{2}$ is the most representative $(60 \%)$ among the pores of the samples. Such displacement to larger values is due to the polymerization reaction kinetics that is quicker than the sample treated at $50{ }^{\circ} \mathrm{C}$. In this case, this observation can be confirmed by rheological analysis (Fig. 2), where the gel time values decreased, with the consequent increase of the complex viscosity, making easier the trapping of volatile material.

Figure $3 \mathrm{c}$ shows the photomicrography and histogram of the polymerized furfuryl sample treated at $70{ }^{\circ} \mathrm{C}$. This sample shows pore areas varying in a range of $100-520 \mu \mathrm{m}^{2}$ with total fractional porosity of $1.85 \%$. The average pore size of $100 \mu \mathrm{m}^{2}$ is the most representative (55\%) among the pores of the samples. Again, in this case the porosity displaced to larger values due to a smaller gel time.

Initially, one must consider that the processing of glassy carbon products requires the casting of the raw resin in a one-step process and the polymerization and carbonization of the resin must provide a $\mathrm{CM}$ with minimum stress concentration and low quantities of microcracks and porosity $^{16}$. As a consequence, the lower temperatures benefit the polymerized resin preparation with lower quantities of voids.

Experimental results show that very good artifacts in glassy carbon can be obtained when the intermediate polymerized materials present a minimum of voids (porosity and microcracks). This study benefits directly the bioengineering area where the pore size can be detrimental to prejudice the use of this material in heart valves and tips of pacemakers electrodes [HP catalogues].

Table 3. Image analysis of the polymerized furfuryl resin at 50, 60 and $70{ }^{\circ} \mathrm{C}$.

\begin{tabular}{lccc}
\hline & \multicolumn{3}{c}{ Polymerized resin } \\
\cline { 2 - 4 } & $50{ }^{\circ} \mathrm{C}$ & $60{ }^{\circ} \mathrm{C}$ & $70{ }^{\circ} \mathrm{C}$ \\
\hline Total porosity $(\%)$ & 1.10 & 1.01 & 1.85 \\
$\begin{array}{l}\text { Fraction more } \\
\text { representative }\left(\mu \mathrm{m}^{2}\right)\end{array}$ & 20 & 40 & 100 \\
$\begin{array}{l}\text { Fraction more } \\
\text { representative }(\%)\end{array}$ & 50 & 60 & 55 \\
Porosity range $\left(\mu \mathrm{m}^{2}\right)$ & $20-85$ & $40-220$ & $100-520$ \\
\hline
\end{tabular}

\section{Conclusions}

If the final properties of $\mathrm{CM}$ to be processed are known, the rheological analysis assisted by chromatographic, thermal and microscopes analysis, is of great importance indicating the best raw materials and the more adequate processing parameters to be used. The support of these techniques allows processing CM to be safe and reliable. Among the studied resin samples, the phenolic type shows itself more adequate to CRFC processing presenting larger gel time values and good values of carbon yield and viscosity. The furfuryl type shows itself applicable to glassy carbon manufacture, presenting lower polymerization temperatures and good values of carbon yield and viscosity.

\section{Acknowledgments}

The authors acknowledge the support from DEMa/UFSCar, IQ/USP-São Carlos, IMA/UFRJ, Resana Ind. Químicas, Cersa Ind. Químicas and Schenectady do Brasil Ltda, FAPESP and CAPES.

\section{References}

1. Jenkins, G.M.; Kawamura, K. Polymeric Carbons - Carbon Fiber, Glass and Char, Cambridge Univ. Press, Cambridge, UK, 1976.

2. Savage, G. Carbon-Carbon Composites, Chapman \& Hall, London, UK, 1993.

3. Fitzer, E. Carbon, v. 25, n. 2, p. 163, 1987.

4. Taylor, R.E.; Kline, D.E. Carbon, v. 16, n. 5, p. 607, 1967.

5. Berglund, L.A.; Kenny, J.M. SAMPE Journal, v. 27, n. 2, p. 27, 1991.

6. Bhatia, G.; Aggarwal, R.K.; Chari, S.S.; Jain, G.C. Carbon, v. 15, n. 4 , p. $219,1977$.

7. Cahn, R.; Haasen, W.P; Kramer, E.J. Materials Science and Technology, v. 9, p.559, 1991.

8. Rahalkar, R.R. Rheologica Acta, v. 29, p. 88, 1990.

9. Franck, A.; Meissner, J. Rheologica Acta, v. 23, p. 117, 1984.

10. Kotaka, T. Journal of Applied Polymer Science, v. 21, p. $501,1977$.

11. McCrackin, F.L. Journal of Applied Polymer Science, v. 21, p. 191, 1977.

12. Rezende, M.C. Produção de Carbono Vítreo, em escala de laboratório, a partir de resinas furfurílicas e fenólicas (volume 1), tese de doutorado, USP, São Paulo, Brazil, 1991.

13. Rodriguez, F. Principles of Polymer Systems, Ed. Taylor \& Francis, $4^{\text {th }}$ edition, Washington, USA, 1996.

14. Cheung, T.; Turpin, M.; Rand, B. Carbon, v. 33, n. 12, p. 1673, 1995.

15. Christiansen, A. W. Journal of Applied Polymer Science, v. 30, p. 2279, 1985.

16. Botelho, E.C. Estudo reológico de resinas fenólicas e furfurílica na obtenção de materiais carbonosos, Dissertação de Mestrado, Instituto Tecnológico de Aeronáutica, São José dos Campos, São Paulo, Brasil, 1998.

17. Yanovsky, Y.G. Polymer rheology theory and practice, Russian Academy of Sciences, Moscow, Rússia, 1993.

18. Cross, M.M. Rheological Acta, v. 18, n. 5, p. 609, 1979. 